\title{
Influence of growth conditions on production of capsular and extracellular polysaccharides by Rhizobium leguminosarum
}

\author{
M.W. Breedveld ${ }^{1,3}$, L.P.T.M. Zevenhuizen ${ }^{1}$, H.C.J. Canter Cremers ${ }^{2,4}$ \& A.J.B. Zehnder ${ }^{1,5}$ \\ ${ }^{I}$ Department of Microbiology, Agricultural University, Hesselink van Suchtelenweg 4, 6703 CT Wageningen, \\ The Netherlands; ${ }^{2}$ Institute of Plant Molecular Biology, State University of Leiden, Nonnensteeg 3 , \\ 2311 VJ Leiden, The Netherlands; (Present addresses: ${ }^{3}$ Department of Food Science, 101 Borland Laboratory, \\ The Pennsylvania State University, University Park, PA 16802, USA $;^{4}$ AHA, Zeemanstraat 35, \\ 2912 BK Nieuwerkerk a/d IJssel, The Netherlands; ${ }^{5}$ EAWAG/ETH, CH-8600 Dübendorf, Switzerland)
}

Received 29 September 1992; accepted in revised form 7 January 1993

Key words: capsular polysaccharide, extracellular polysaccharide, polysaccharide production, Rhizobium leguminosarum

\begin{abstract}
The influence of growth rate and medium composition on exopolymer production by Rhizobium leguminosarum was studied. When grown in medium containing $10 \mathrm{~g} / 1$ mannitol and $1 \mathrm{~g} / 1 \mathrm{glutamic}$ acid, Rhizobium leguminosarum biovar trifolii TA-1 synthesized up to $2.0 \mathrm{~g} / \mathrm{l}$ of extracellular polysaccharide (EPS), and up to $1.6 \mathrm{~g} / 1$ of capsular polysaccharide (CPS). Under non-growing cell conditions in medium without glutamic acid, CPS synthesis by strain TA-1 could proceed to $2.1 \mathrm{~g} / \mathrm{l}$, while EPS-production remained relatively low $(0.8 \mathrm{~g} / \mathrm{l})$. Maximal CPS-yield was $2.9 \mathrm{~g}$ CPS/1 medium in a medium containing $20 \mathrm{~g} / \mathrm{l}$ mannitol and $2 \mathrm{~g} / \mathrm{l}$ glutamic acid. The EPS-deficient strain R. leguminosarum RBL5515,exo4::Tn5 was able to produce CPS to similar levels as strain TA-1, but CPS-recovery was easier because of the low viscosity of the medium and growth of the cells in pellets. With strain TA-1 in nitrogen-limited continuous cultures with a constant biomass of $500 \mathrm{mg}$ cell protein/l, EPS was the most abundant polysaccharide present at every dilution rate D (between 0.12 and $0.02 \mathrm{~h}^{-1}$ ). The production rates were $50-100 \mathrm{mg} / \mathrm{g}$ protein $/ \mathrm{h}$ for EPS and $15-20 \mathrm{mg} / \mathrm{g}$ protein $/ \mathrm{h}$ for CPS. Only low amounts of cyclic $\beta-(1,2)$-glucans were excreted $(10-30 \mathrm{mg} / 1)$ over the entire range of growth rates.
\end{abstract}

Abbreviations: bv - biovar; CPS - capsular polysaccharide; EPS - extracellular polysaccharide; $\mathrm{HM}_{\mathrm{r}}$ - high molecular mass; $\mathrm{LM}_{\mathrm{r}}$ - low molecular mass; YEMCR - Yeast Extract-Mannitol-Congo Red agar

\section{Introduction}

Many Gram-negative and Gram-positive bacteria are capable of synthesizing a variety of polysaccharides (Sutherland 1988). Rhizobium leguminosarum strains produce exopolysaccharides such as high molecular weight anionic extracellular polysaccharide (EPS), insoluble neutral capsular polysaccharide (CPS) and cellulosic microfibrils. In ad- dition, cyclic $\beta-(1,2)$-glucans secreted from the periplasm can be found in the medium (Zevenhuizen 1990). The EPS type commonly found with this group of organisms is composed of an octasaccharide repeating unit with sugar composition of glucose:glucuronic acid:galactose in the ratios of $5: 2: 1$ (McNeil et al. 1986). The CPS from a number of $R$. leguminosarum strains, composed of neutral sugars without any non-sugar substituents, has a constant 
sugar composition of glucose:galactose:mannose in the ratios of 1:4:1 (Zevenhuizen 1984). CPS of $R$. $l e$ guminosarum is a polymer with a minimal critical gel concentration at $0.01 \% \mathrm{w} / \mathrm{v}$, which is even less than the $0.02 \%$ for agarose (Zevenhuizen 1984; Gidley et al. 1987; Crescenzi et al. 1987).

Like all fast-growing rhizobia, $R$. leguminosarum bv trifolii TA-1 is multi-productive with respect to polysaccharide-production. A selective synthesis of polysaccharides can be achieved with this strain in mannitol-rich media, such as: (i) EPS under forced aeration (Zevenhuizen 1986), (ii) CPS in fed-batch cultures (Zevenhuizen 1986), or (iii) cyclic $\beta-(1,2)$ glucans at superoptimal temperature of growth or at high osmotic pressures of the medium (Breedveld et al. 1990, 1991). In the present study the production of EPS and CPS by strain TA-1 was further investigated, and the distribution of these polymers was studied as a function of growth rate and composition of the medium. Since CPS production was often accompanied by high EPS-production, batch incubations of strain TA-1 were compared with that of an EPS-deficient strain $R$. leguminosarum RBL5515,exo4::Tn5. This strain was able to produce mainly CPS at low viscosity of the culture due to low EPS-production.

\section{Materials and methods}

\section{Organisms and cultivation}

Organisms. Rhizobium leguminosarum bv trifolii TA-1 was obtained from the culture collection of the Department of Microbiology, Wageningen, The Netherlands. R. leguminosarum RBL5515, exo4::Tn5 (Canter et al. 1988), a mutant of $R$. leguminosarum RBL5515 cured for its symbiotic plasmid, was obtained from the culture collection of the Institute of Plant Molecular Biology, State University Leiden, The Netherlands.

Media. The standard medium contained $5 \mathrm{~g}$ mannitol and $1 \mathrm{~g}$ glutamic acid per liter, and mineral salts and vitamins as described (Breedveld et al. 1990). Its carbon/nitrogen $(\mathrm{C} / \mathrm{N})$ ratio of 29 made it a nitrogenlimited medium. Often the production medium was used, which contained $10 \mathrm{~g}$ of mannitol, sucrose, glucose or galactose per liter as carbon and energy source, and $1 \mathrm{~g}$ glutamic acid or $0.36 \mathrm{~g} \mathrm{NH}_{4} \mathrm{Cl}$ per liter as nitrogen source. The $\mathrm{pH}$ of the medium was adjusted to 7.0 with $\mathrm{NaOH}$ or $\mathrm{HCl}$ before sterilization.

Batch cultivation. Precultures were prepared by inoculating the organism into standard medium. Cells from the late logarithmic phase were inoculated $(1 \% ; \%)$ into $50 \mathrm{ml}$ of medium in $300 \mathrm{ml}$ Erlenmeyer flasks. The flasks were incubated on a rotary shaker at $200 \mathrm{rpm}$ at $25^{\circ} \mathrm{C}$ for various incubation times. For non-growing cell cultures, $72 \mathrm{~h}$ grown cells were collected by centrifugation, and the cell pellet was transferred to glutamic acid-free production medium containing $10 \mathrm{~g} / \mathrm{l}$ mannitol. The fed-batch experiment was carried out in $1 l$ of medium in a $2 l$ vessel aerated at $1 l$ air $/ \mathrm{min}$, impeller speed $600 \mathrm{rpm}$.

Continuous cultivation. For continuous culture experiments TA- 1 cells grown for $72 \mathrm{~h}$ in standard medium were inoculated $1 \%(\mathrm{v} / \mathrm{v})$ in $1 l$ of production medium in a $2 l$ vessel aerated at $1 l$ air $/ \mathrm{min}$, impeller speed $600 \mathrm{rpm}$. In this way, the oxygen tension never fell below $25 \%$ air saturation at $25^{\circ} \mathrm{C}$. The culture was run the first $24 \mathrm{~h}$ in the batch mode. Thereafter, it was operated as a chemostat. Samples were taken at certain D-values after steady-state had been reached (routinely after 5 volume changes). The $\mathrm{pH}$ was kept at 7.0 with $2 \mathrm{~N} \mathrm{NaOH}$ and $2 \mathrm{~N} \mathrm{HCl}$. To prevent foaming, 1 drop of polypropylene-glycol was added if needed.

Two-step continuous cultivation was carried out with the first fermentor containing $0.5 l$ production medium and run at $\mathrm{D}=0.11 \mathrm{~h}^{-1}$. The outlet was connected to a $10 l$ vessel with a working volume of $4.4 l$ run at $\mathrm{D}=0.021 \mathrm{~h}^{-1}$. This vessel was aerated at $0.5 l \mathrm{air} / \mathrm{min}$ and $l$ volume, and stirred by a magnetic stirrer.

Purity of the cultures was routinely checked by plating appropriate dilutions on Yeast Extract-Mannitol-Congo Red (YEMCR) agar (Zevenhuizen et al. 1986). Cell shape and uniformity of the culture were also checked by phase-contrast microscopy. 
Analytics

Cells and the culture medium were separated by centrifugation at $35000 \times \mathrm{g}$ for $30 \mathrm{~min}$. The cell pellet was resuspended fivefold of the original concentration in distilled water and briefly sonicated to obtain a homogeneous suspension.

To measure growth 2 methods were used: (i) total cellular protein content of the pellet was measured according to Lowry et al. (1951) after pretreatment of the cell pellet in $\mathrm{N} \mathrm{NaOH}$ at $100^{\circ} \mathrm{C}$ for $30 \mathrm{~min}$; (ii) from the slope of a growth curve (optical density at $660 \mathrm{~nm}$ versus time); during the early exponential phase of growth in batch culture the maximum specific growth rate was determined. In this phase of growth a linear relationship existed between optical density and cell protein content (Breedveld 1992).

Extracellular carbohydrates were determined in the supernatant by the anthrone-sulphuric acid method for hexuronic acids (Blumenkrantz \& Asboe-Hansen 1973). The concentration of EPS and cyclic glucans were calculated as described (Breedveld et al. 1990).

Cellular carbohydrates were determined in the pellet as described (Breedveld et al. 1990). The alkali-extracted cells were measured for glycogen and cellulose as described (Zevenhuizen et al. 1986).

Isolation of $\mathrm{HM}_{\mathrm{r}}$ EPS and CPS was carried out as described (Zevenhuizen 1986).

Mannitol was determined in the culture supernatant fraction by periodate oxidation followed by the chromotropic acid-colorimetric method (Burton 1957).

The viscosity of the culture supernatant fraction was measured with an Ubbelohde viscometer (Tamson, Zoetermeer, The Netherlands) at $25^{\circ} \mathrm{C}$.

\section{Results}

\section{Yields and production rates of polysaccharides}

\section{Nitrogen source}

$\mathrm{NH}_{4}^{+}$is the preferred nitrogen source for several species of Rhizobium at constant pH (Poole et al. 1987). Other strains prefer an organic nitrogen source like glutamate (Bergensen 1961). These two nitrogen sources were compared for strain TA-1, on the basis of the same nitrogen-equivalents. The buffer capacity of the phosphate-buffered medium $(5.8 \mathrm{mM} ; \mathrm{pH}=7.0)$ with $\mathrm{NH}_{4} \mathrm{Cl}$ as nitrogen-source was not enough to prevent acidification of the medium. When $\mathrm{CaCO}_{3}$ was added to the medium, acidification could be prevented. EPS-yields were better with $\mathrm{NH}_{4} \mathrm{Cl}$ (in the presence of $\mathrm{CaCO}_{3}$ ) as compared to glutamic acid as nitrogen-source. However, CPS synthesis was much higher with glutamic acid as nitrogen source (Table 1: a-c).

\section{Carbon source and its concentration}

Mannitol is a good carbon and energy source for fast-growing rhizobia (Stowers 1985). The influence of the concentration of mannitol on the polysaccharide production was investigated (Fig. 1). In media with a higher concentration of mannitol than necessary for biomass production ( $\geq 2 \mathrm{~g}$ mannitol/1) polysaccharide production was enhanced. High concentrations of mannitol led to viscous cultures due to the high EPS production. The highest CPS/EPS ratio was achieved in the production medium. The generation time of strain TA- 1 in production medium was calculated to be $g=5.3 \mathrm{~h}$, or maximum specific growth rate of $\mu_{\max }=0.133 \mathrm{~h}^{-1}$. In the production medium the CPS production rate in stationary phase (during 11 days) was calculated to be $13 \mathrm{mg}$ CPS/g protein.h. EPS was produced during logarithmic growth phase, with a rate of $75 \mathrm{mg}$ EPS $/ \mathrm{g}$ protein $\cdot h$, and diminished during stationary phase (not shown), comparable to earlier observations (Zevenhuizen 1986).

The substrates sucrose, glucose, and galactose were compared with mannitol, on the basis of the same carbon equivalents. With glucose and galactose as substrate the medium quickly acidified, which could be prevented by adding $\mathrm{CaCO}_{3}$. The CPS production with glucose and galactose as substrate was lower than with mannitol or sucrose (Table 1: a, d-h). Sucrose is comparable to mannitol as substrate with respect to EPS and CPS production. For laboratory experiments, mannitol is most convenient, since it does not interfere with the hexose measurements and can easily be measured separately. However, on a large scale sucrose would be more favorable, for economical reasons. 
In an attempt to increase the volumetric yields of CPS the concentrations of both glutamic acid and mannitol in the production medium were increased by a factor of 2. CPS-production reached $2900 \mathrm{mg} / 1$ of medium on a basis of $1 \mathrm{~g}$ protein (Table 1: i), with a rate of $10 \mathrm{mg}$ CPS $/ \mathrm{g}$ protein $\mathrm{h}$. In the culture medium, $600-800 \mathrm{mg} / \mathrm{l}$ of cyclic glucans were found. This experiment was repeated in a bath-fermenter with $\mathrm{pH}$ set at 7.0 and saturated oxygen concentration. No significant differences were observed as compared to the results with the shaking flasks experiment (Table 1: i). Higher substrate concentration lead to a decreased CPS-synthesis (Breedveld et al. 1990). When supplying the mannitol in a fed-batch mode, comparable results for CPS were obtained, but EPS synthesis and cyclic glucan excretion were lower (Table 1: j).

Since CPS synthesis was only manifest during stationary phase, batch experiments were carried out in which the growth phase was separated from the CPS-production phase. Under these non-growing cell conditions, polysaccharides were measured after a total incubation time of 14 days (Table 1: $\mathrm{k}$ ). CPS production reached $2100 \mathrm{mg} / \mathrm{l}$, and the EPSproduction was relatively low, with a concomitant low viscosity of $5.9 \mathrm{cP}$.

\section{CPS-production in the EPS-deficient strain RBL5515, exo4::Tn5}

Since CPS-production in stationary phase was often overshadowed by a high EPS production, which already started in logarithmic growth phase, the polysaccharide production pattern of the EPS-deficient strain RBL5515,exo4::Tn5 was investigated. Earlier this mutant strain was selected because of its rough appearance on agar plates (Canter Cremers 1990). The production of EPS by this mutant was reduced by more than $90 \%$, but the chemical composition was the same as the EPS of the wildtype strain RBL5515 (Canter Cremers 1990). The structural properties of the polysaccharides of strain TA-1 and wildtype strain RBL5515 were found to be very similar (Breedveld 1992). The mutation did not affect the growth rate, which was very similar to strain TA-1 (data not shown). The yield of CPS was very much comparable to strain TA-1 (Table 2), with a production rate of $11 \mathrm{mg} \mathrm{CPS} / \mathrm{g}$ protein $\mathrm{h}$. Recovery of CPS was easier due to the low viscosity of the medium. As compared to wildtype strains, two noteable differences were the enhanced excretion of cyclic glucans into the medium (Table 2), and an increased ability of the cells to grow in pellets. To

Table 1. Influence of the carbon- and nitrogen-source on polysaccharide-yields by Rhizobium leguminosarum bv trifolii TA-1 in batch cultures incubated for 14 days at $25^{\circ} \mathrm{C}$.

\begin{tabular}{|c|c|c|c|c|c|c|c|c|}
\hline & C-source $(\mathrm{g} / \mathrm{l})$ & $\begin{array}{l}\text { N-source } \\
(5.8 \mathrm{mM})\end{array}$ & $\begin{array}{l}\mathrm{CaCO}_{3} \\
(1 \mathrm{~g} / \mathrm{l})\end{array}$ & $\begin{array}{l}\mathrm{HM}_{\mathrm{r}} \mathrm{EPS} \\
(\mathrm{mg} / \mathrm{l})\end{array}$ & $\begin{array}{l}\text { glucans } \\
(\mathrm{mg} / \mathrm{l})\end{array}$ & $\mathrm{pH}$ & $\begin{array}{l}\text { CPS } \\
(\mathrm{mg} / 1)\end{array}$ & $\begin{array}{l}\text { protein } \\
(\mathrm{mg} / \mathrm{l})\end{array}$ \\
\hline $\mathrm{a}$ & Mannitol (10) & Glut.acid & - & 1900 & 30 & 7.2 & 1600 & 520 \\
\hline b & Mannitol (10) & $\mathrm{NH}_{4} \mathrm{Cl}$ & - & 400 & 60 & 4.7 & 80 & 410 \\
\hline c & Mannitol (10) & $\mathrm{NH}_{4} \mathrm{Cl}$ & + & 2100 & 70 & 6.9 & 600 & 510 \\
\hline d & Sucrose $(10)$ & Glut.acid & - & $1680^{1)}$ & 2) & 7.0 & 1470 & 530 \\
\hline $\mathrm{e}$ & Glucose $(10)$ & Glut.acid & - & $580^{1)}$ & 2) & 5.7 & 300 & 490 \\
\hline f & Glucose $(10)$ & Glut.acid & + & $1580^{1)}$ & 2) & 8.0 & 980 & 510 \\
\hline $\mathrm{g}$ & Galactose (10) & Glut.acid & - & $560^{1\rangle}$ & 2) & 5.6 & 310 & 450 \\
\hline h & Galactose (10) & Glut.acid & + & $1760^{1)}$ & 2) & 8.1 & 870 & 520 \\
\hline $\mathrm{i}$ & Mannitol (20) & $2 \times$ Glut.acid $^{3)}$ & - & 1400 & 800 & 7.6 & 2900 & 1050 \\
\hline j & Mannitol $(20)^{4)}$ & $2 \times$ Glut.acid $^{4)}$ & - & 900 & 650 & 7.4 & 2800 & 990 \\
\hline $\mathrm{k}$ & Mannitol (10) & $-5\}$ & - & 800 & 40 & 7.4 & 2100 & 510 \\
\hline
\end{tabular}

1) $\mathrm{HM}_{\mathrm{r}}$ EPS was determined after precipitation and washing with $3 \mathrm{vol}$ alcohol, and then expressed as glucose+ glucuronic acid in mg/l culture because of interference by hexose containing substrates during direct measurements in the medium; 2) Glucans were not determined because of interference by hexose-containing substrates; 3 ) Incubation in 2 times concentrated production medium (containing $20 \mathrm{~g} / \mathrm{l}$ mannitol and $2 \mathrm{~g} / \mathrm{l}$ glutamic acid $(11.6 \mathrm{mM})$ ); 4) Incubation in fed-batch system composed of $2 \mathrm{~g} / \mathrm{l}$ glutamic acid and $5 \mathrm{~g} / \mathrm{l} \mathrm{mannitol}$. After $60 \mathrm{~h}$ and $180 \mathrm{~h}$ mannitol is added, $10 \mathrm{~g} / \mathrm{l} \mathrm{resp.} 5 \mathrm{~g} / \mathrm{l} ; 5)$ Cells are transferred after $72 \mathrm{~h}$ from production medium to glutamic acid-free production medium. 


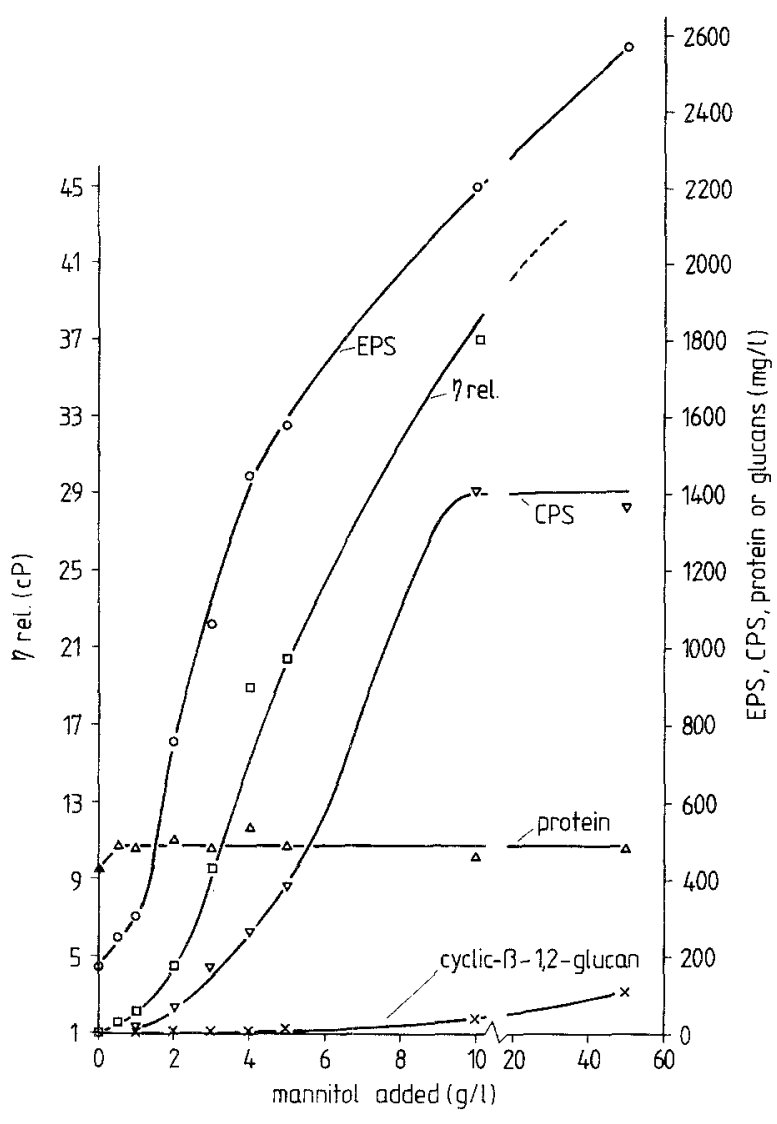

Fig. 1. Effect of the concentration of mannitol in the medium on extracellular and capsular polysaccharide production of Rhizobium leguminosarum bv trifolii TA-1 grown in batch culture for 14 days. $\eta$ rel. $=$ viscosity of the medium in $\mathrm{cP}$ (centipoise). increase the volumetric CPS yields of the EPS-deficient strain RBL5515,exo4::Tn5 the concentration of nutrients of the medium was increased. In a medium containing twice the amount of the nutrients of the production medium, biomass increased proportionally, but the CPS production increased only by a factor of 1.2 (Table 2). By further increasing the concentration of nutrients of the production medium, CPS synthesis was strongly repressed. Under these circumstances protein was found in the supernatant, indicating that considerable cell lysis had occurred. The CPS production by strain RBL5515,exo4::Tn5 in concentrated standard media was reduced as well (Table 2). Instead, cyclic glucan excretion was greatly enhanced, as was shown for strain TA-1 (Breedveld et al. 1990). The viscosity of the medium remained low due to a low EPS production.

\section{Continuous culture experiments}

The influence of the growth rate on production of polysaccharides by strain TA-1 was investigated in a continuous culture. After reaching steady state cell protein, mannitol consumption and polysaccharide production were measured at different dilution rates D (Fig. 2). EPS was synthesized at both high and low growth rates and was the predominent polysaccharide produced, while CPS synthesis oc-

Table 2. Influence of concentration of medium components on polysaccharide synthesis by $R$. leguminosarum mutant RBL5515,exo4::Tn5. Cells were incubated for 14 days at $25^{\circ} \mathrm{C}$.

\begin{tabular}{|c|c|c|c|c|c|c|}
\hline \multicolumn{2}{|l|}{ Medium } & \multicolumn{3}{|l|}{ Supernatant } & \multicolumn{2}{|l|}{ Pellet } \\
\hline & $\begin{array}{r}\text { Osmotic pressure } \\
(\mathrm{MPa})\end{array}$ & EPS (mg/l) & glucans (mg/l) & protein (mg/l) & CPS (mg/l) & Protein $(\mathrm{mg} / \mathrm{l})$ \\
\hline standard & 0.14 & 150 & 280 & 0 & 480 & 475 \\
\hline production & 0.20 & 160 & 430 & 0 & 1630 & 530 \\
\hline $2 \times$ standard $^{\mathrm{b})}$ & 0.28 & 250 & 650 & 30 & 570 & 1110 \\
\hline $2 \times$ production $^{\text {b) }}$ & 0.40 & 270 & 850 & $\mathrm{nd}^{\mathrm{a})}$ & 1940 & 1050 \\
\hline $4 \times$ standard $^{\mathrm{b})}$ & 0.55 & 465 & 3800 & 375 & 240 & 1880 \\
\hline $8 \times$ standard $^{\text {b) }}$ & 1.10 & 470 & 8400 & 1650 & 200 & 2900 \\
\hline $10 \times$ standard $^{\text {b) }}$ & 1.38 & 500 & 11900 & 1800 & 310 & 3250 \\
\hline
\end{tabular}

${ }^{a)} \mathrm{nd}=$ not determined.

b) $2 \times$ standard is a medium consisting of twice the amount of substrates and nutrients of the standard medium, $2 \times$ production is a medium with twice the amount of nutrients and substrates of the production medium, etc. 


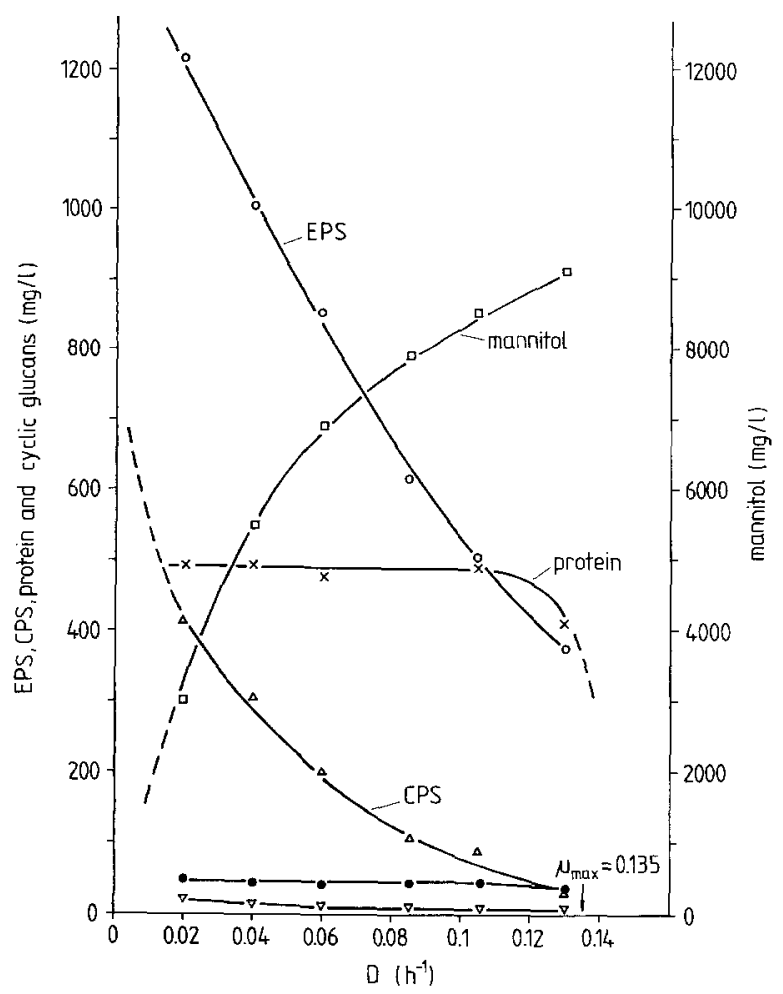

Fig. 2. Effect of the dilution rate $\mathrm{D}$ on polysaccharide production of Rhizobium leguminosarum bv trifolii TA-1 in a continuous culture in production medium. $\square=$ mannitol; $O=E P S ; \triangle=C P S$; - $\nabla=$ intracellular and extracellular cyclic glucans, respectively; $\mathrm{x}=$ protein.

curred only at much lower production rates. Production rates in continuous culture for EPS ranged from 100 to $45 \mathrm{mg} / \mathrm{g}$ protein $\mathrm{h}$ at $\mathrm{D}=0.1$ and $\mathrm{D}=$ $0.02 \mathrm{~h}^{-1}$, respectively. CPS-production rates varied from 20 to $16 \mathrm{mg} C P S / g$ protein $h$ as can be calculated from the diagram (Fig. 2).
The intracellular concentration of cyclic glucans at different growth rates ranged between 35 $45 \mathrm{mg} / \mathrm{l}$ medium (about $70-90 \mathrm{mg} / \mathrm{g}$ protein). The supernatant contained only $10-30 \mathrm{mg} / \mathrm{l}$ of cyclic glucans. At all growth rates except around $\mu_{\max }$, cell counts were $(3 \pm 0.2) \times 10^{10} / \mathrm{ml}$. Upon prolonged cultivation at $\mathrm{D}=0.10 \mathrm{hr}^{-1}$ variants of the TA-1 colonies could be observed on YEMCR plates at a frequency of $0.0001-0.01 \%$ at 5-25 volume changes, respectively, as was shown previously (Zevenhuizen 1984, 1986). These colonies took up the Congo red dye intensively. The variants contained up to $150 \mathrm{mg}$ cellulose/g protein in their cell pellets, while in most cases $20-60 \mathrm{mg} / \mathrm{g}$ protein was measured (data not shown). However, the production pattern and structures of EPS and CPS were not altered in these variants. At low growth rates, below $0.02 \mathrm{~h}^{-1}$, EPS made the medium highly viscous (viscosity of the medium $\geq 15 \mathrm{cP}$ ). Furthermore, heavy wall growth occurred by the cellulose-producing variants.

\section{Two-step cultivation}

Since CPS was found to be produced only at low dilution rates, polysaccharide production in a 2-step continuous culture was investigated. In the first fermenter (the continuous culture vessel) biomass was produced at a constant $\mathrm{D}=0.11 \mathrm{~h}^{-1}$. In the second step $\left(\mathrm{D}=0.021 \mathrm{~h}^{-1}\right)$ no growth occurred, since all the glutamic acid was already consumed. However, polysaccharide production could proceed since the influent still contained mannitol. Despite the nongrowth-conditions in this second vessel EPS was still the main polysaccharide present (Table 3 ; cc1, cc2).

When the second vessel was disconnected from the first fermentor and further incubated in batch

Table 3. Polysaccharide-production by Rhizobium Leguminosarum bv. trifolii TA-1 in the two stage fermentor system. cc1= first fermentor run at $\mathrm{D}=0.11 \mathrm{~h}^{-1} ; \mathrm{cc} 2=$ second fermentor run at $\mathrm{D}=0.021 \mathrm{~h}^{-1} ; \mathrm{cc} 2$-batch $=\mathrm{cc} 2$-production vessel cultivated in batch-mode, during 5 days.

\begin{tabular}{|c|c|c|c|c|c|c|}
\hline \multirow[t]{2}{*}{ Vessel } & \multirow[t]{2}{*}{ Growth rate $\left(\mathrm{h}^{-1}\right)$} & \multicolumn{3}{|l|}{ Supernatant } & \multicolumn{2}{|l|}{ Pellet } \\
\hline & & mannitol $(\mathrm{g} / \mathrm{l})$ & EPS (mg/l) & glucans (mg/l) & CPS (mg/l) & glucans (mg/l) \\
\hline $\mathrm{cc} 1$ & 0.11 & 8.8 & 510 & 5 & 110 & 35 \\
\hline $\operatorname{cc} 2$ & 0.021 & 4.8 & 1100 & 10 & 550 & 45 \\
\hline cc2-batch & 0 & 0.2 & 1650 & 45 & 1290 & 55 \\
\hline
\end{tabular}

See legend Table 1 for explanation. 
mode for another 5 days (Table 3: batch), EPS and CPS production in this aerated and stirred vessel was comparable to that obtained in a conventional batch culture.

\section{Discussion}

In batch and continuous cultures of Rhizobium leguminosarum by trifolii strain TA-1 EPS was often the most predominent polysaccharide present, while CPS-synthesis only became apparent in media with excess carbon at low dilution rates or in stationary phase (Zevenhuizen 1986, this study). With increasing concentrations of EPS in the medium, EPS-production rates decreased, both in continuous cultures at lower dilution rates, and in batch cultures during prolonged incubation. Furthermore, it is likely that high EPS-concentrations give rise to a lower diffusion rate of oxygen to the cells because of the high viscosity of the medium. With incubations with forced aeration such as in Kluyverflasks (Zevenhuizen 1986) a much higher EPS production was achieved creating a high viscosity. Continuous cultivation aimed at polysaccharideproduction is only beneficial for EPS, because its synthesis is growth-associated. In the two-step fermentation process EPS synthesis was predominant since only the growth rates were separated. By separating cells from supernatant in the non-growing cell-experiment, CPS synthesis took place in a medium with lower viscosity due to low EPS-production. Although yields of the different polysaccharides greatly differed between different culture conditions, the hexose compositions of both CPS and EPS of strain TA-1 were independent of growth phase and/or medium composition (data not shown).

Variation in polysaccharide production may be sometimes observed in different batches. Earlier it was observed that a small number of colonies of strain TA-1 had a different colour uptake on Congo red-containing agar (YEMCR) plates (Zevenhuizen 1984). These mutant strains were abundant in quantitatively high amounts when cultured for a longer time in the chemostat and contained high amounts of cellulose (Zevenhuizen 1984). Furthermore, on agar plates both slimy colonies, leading to highly viscous cultures in liquid medium, and very small colonies appeared (Zevenhuizen 1987, unpublished observations). The latter variant, which showed relatively low viscosities $(5 \mathrm{cP})$ in liquid standard medium, was likely predominant in the earlier experiments (Zevenhuizen 1984). From the experiments presented in this paper, it appears that the highly viscous variant was predominant in all batch culture-experiments, while in the continuous culture during prolonged incubation the high-cellulose containing variant appeared as well. Therefore, not only the cultural conditions are important in assessing the selective synthesis of polysaccharides, but also the fact that one particular strain may contain a collection of different variants. However, in media with excess carbon source, the CPS-production rates did not differ much between the different variants, varying between 10 and $20 \mathrm{mg} C P S / g$ protein'h (Zevenhuizen 1984; Zevenhuizen et al. 1986), comparable to the present study.

The CPS of $R$. leguminosarum is unique in its chemical composition and interesting for its physical properties (Gidley et al. 1987). Because of its specific properties it would be interesting to find conditions optimal for high CPS yields. The highest yield (2.9g CPS/l) was found in a 2-times concentrated production medium, comparable to $3.0 \mathrm{~g} / \mathrm{l}$ found for TA-1 in a fed-batch culture (Zevenhuizen 1986). Incubation times longer than 14 days may lead to higher CPS-yields, if mannitol is still present. However, higher substrate concentrations in batch cultures resulted in higher cell mass and higher EPS-production, but decreased CPS synthesis and enhanced cyclic $\beta$-(1,2)-glucan excretion (Breedveld et al. 1990, this study). Apparently the synthesis of CPS is tightly regulated, but its mechanism is not yet known. Suboptimal conditions, such as superoptimal temperature for growth $\left(33^{\circ} \mathrm{C}\right)$ and higher osmolarity of the medium (osmotic pressure $0.75-1.5 \mathrm{MPa}$ ), lead to a strong repression of CPS synthesis (Breedveld et al. 1990, 1991). Exopolysaccharide synthesis by $R$. meliloti $\mathrm{sp}$. stopped when the $\mathrm{pH}$ fell below 6 during exponential growth (Courtois et al. 1979). In cultures of strain TA-1, the drop in $\mathrm{pH}$ as a result of growth on glucose, galactose, or $\mathrm{NH}_{4} \mathrm{Cl}$ repressed EPS, but in particular CPS synthesis. 
The CPS production of the EPS-deficient strain RBL5515,exo4::Tn5 was comparable to strain TA-1. At increasing osmotic strength of the medium (pressure $>0.5 \mathrm{MPa}$, Table 2) a shift could be observed from CPS to cyclic $\beta-(1,2)$-glucan synthesis, as was shown for strain TA-1 (Breedveld et al.1991). In order to be able to produce CPS at high cell concentrations, the osmotic pressure of the culture medium should stay below $0.5 \mathrm{MPa}$, both during the logarithmic phase of growth and during synthesis of CPS. Therefore, by applying different cultural conditions, strain RBL5515,exo4::Tn5 produced CPS (at low osmolarity of the medium) or cyclic glucans (at high osmolarity of the medium) as the main polysaccharides. The low viscosity of the medium and their growth in pellets make these kind of mutants advantageous as production organisms of CPS and/ or cyclic (1,2)- $\beta$-glucans over all wildtype Rhizobium strains investigated thus far.

\section{Acknowledgements}

Nees Slotboom is acknowledged for drawing the figures. Jill Hadley is acknowledged for critically reading the manuscript. This investigation was carried out with the support of the Dutch National Innovation Oriented Program Carbohydrates (IOP-k).

\section{References}

Blumenkrantz M \& Asboe-Hansen O (1973) New method for the quantitative determination of uronic acids. Anal. Biochem. 54: 484-489

Bergersen FJ (1961) The growth of Rhizobium in synthetic media. Austr. J. Biol. Sc. 14: 349-360

Breedveld MW (1992) Oligo- and Polysaccharide synthesis by Rhizobium leguminosarum and Rhizobium meliloti. PhD thesis, Wageningen Agricultural University, The Netherlands

Breedveld MW, Zevenhuizen LPTM \& Zehnder AJB (1990) Excessive excretion of cyclic $\beta$-(1,2)-glucan by Rhizobium trifolii TA-1. Appl. Environ. Microbiol. 56: 2080-2086

- (1991) Osmotically-regulated trehalose accumulation and cyclic $\beta-(1,2)$-glucan excretion by Rhizobium leguminosarum biovar trifolii TA-1. Arch, Microbiol. 156: 501-506
Burton RM (1957) The determination of glycerol and dihyroxyacetone. In: Colowick SP \& Kaplan NO (Eds) Methods in Enzymology, part III (pp 246-249). Acad. Press, New York

Canter Cremers HCJ (1990) Role of exopolysaccharide in nodulation by Rhizobium leguminosarum bv viciae. $\mathrm{PhD}$ thesis, State University of Leiden, The Netherlands

Canter Cremers HCJ, Wijffelman CA, Pees E, Engels M, Hoogerbruggen F, Stevens K, van Dijk M \& Lugtenberg BJJ (1988) Chromosomal nodulation genes of $R$. leguminosarum biovar viciae. In: Bothe H, de Bruijn FJ \& Newton WJ (Eds) Nitrogen fixation: hundred years after (p484). Gustav Fisher, Stuttgart, Germany

Courtois B, Hornez JP \& Derieux JC (1979) Effect de la synthèse d'acide 2-cétogluconique sur la production d'exopolysaccharides par une souche de Rhizobium meliloti. Can. J. Microbiol. 25: 1191-1196

Crescenzi V, Dentini M, Coviello T, Paoletti S, Cesaro A \& Delben $F$ (1987) On the solution and gelling behaviour of some bacterial polysaccharides. Gazz. Chim. Ital. 117: 611-616

Gidley MJ, Dea ICM, Eggleston G \& Morris ER (1987) Structure and gelation of Rhizobium capsular polysaccharides. Carbohydr. Res. 160: 381-396

Lowry OH, Rosebrough AL, Farr RJ \& Randall RJ (1951) Protein measurements with the Folin phenolreagent. J. Biol. Chem. 193: 265-275

McNeil MA, Darvill J, Darvill AG, Albersheim P, van Veen A, Hooykaas P \& Schilperoort RH (1986) The discernable features of the acidic exopolysaccharides secreted by different Rhizobium species are the same. Carbohydr. Res. 146: 307326

Poole PS, Dilworth MJ \& Glenn AR (1987) Ammonia is the preferred nitrogen source in several Rhizobia. J. Gen. Microbiol. 133: $1707-1712$

Stowers MD (1985) Carbon-utilization by Rhizobium. Ann. Rev. Microbiol. 34: 89-108

Sutherland IW (1988) Bacterial surface polysaccharides: structure and function. Internat. Rev. Cytol. 113: 187-231

Trevelyan WE \& Harrison JS (1952) Studies on yeast metabolism I. Fractionation and microdetermination of cell carbohydrates. Biochem. J. 50: 298-310

Zevenhuizen LPTM (1984) Gel-forming capsular polysaccharide of fast-growing rhizobia: occurrence and rheological properties. Appl. Microbiol. Biotechnol. 20: 393-399

- (1986) Selective synthesis of polysaccharides by Rhizobium trifolii strain TA-1. FEMS Microbiol. Lett. 35: 43-47

- (1990) Recent developments in Rhizobium polysaccharides. In: Dawes EA (Ed) Biodegradable Microbial Polymers (pp 387-402). Kluwer Publishers, Dordrecht, The Netherlands

Zevenhuizen LPTM, Bertocchi C \& Van Neerven ARW (1986) Congo-red absorption and cellulose synthesis by Rhizobiaceae. Antonie van Leeuwenhoek 52: 381-386 